\title{
Anaerobic cultures from preserved tissues of baby mammoth
}

\author{
Elena V. Pikuta*, Daniel Fisher ${ }^{* *}$ and Richard B. Hoover ${ }^{*}$ \\ * NSSTC/NASA 320 Sparkman Dr., Huntsville, AL 35805 USA; phone: 1256 961-7868; 1256 961-7770; e-mail: \\ pikutae@UAH.edu; Richard.Hoover@NASA.GOV \\ ** Uniersity of Michigan 1109 Geddes Ave., Ann Arbor, Michigan 48109-1079 USA e-mail: dcfisher@umich.edu \\ Phone:1 (734) 764-0488
}

\begin{abstract}
Microbiological analysis of several cold-preserved tissue samples from the Siberian baby mammoth known as Lyuba revealed a number of culturable bacterial strains that were grown on anaerobic media at $4{ }^{\circ} \mathrm{C}$. Lactic acid produced by LAB (lactic acid bacteria) group, usually by members of the genera Carnobacterium and Lactosphera, appears to be a wonderful preservative that prevents other bacteria from over-dominating a system. Permafrost and lactic acid preserved the body of this one-month old baby mammoth and kept it in exceptionally good condition, resulting in this mammoth being the most complete such specimen ever recovered.

The diversity of novel anaerobic isolates was expressed on morphological, physiological and phylogenetic levels. Here we discuss the specifics of the isolation of new strains, differentiation from trivial contamination, and preliminary results for the characterization of cultures.
\end{abstract}

Key words: anaerobic bacteria, mammoth, permafrost, lactic acid 